\title{
Sustainable Lighting-Retrofit Versus Dedicated Luminaires-Light Versus Power Quality
}

\author{
Calin Ciugudeanu ${ }^{1, *} \mathbb{C}$, Mircea Buzdugan ${ }^{1}$, Dorin Beu ${ }^{1}$, Angel Campianu ${ }^{1}$ and \\ Catalin Daniel Galatanu ${ }^{2}$ \\ 1 Building Services Faculty, Technical University of Cluj-Napoca, Cluj-Napoca 400114, Romania; \\ mircea.buzdugan@insta.utcluj.ro (M.B.); dorin.beu@rogbc.com (D.B.); angel.campianu@insta.utcluj.ro (A.C.) \\ 2 Civil Engineering and Building Services Faculty, Technical University “Gh. Asachi” Iași, Bd. Mangeron 67, \\ Iasi 700050, Romania; catalin.galatanu@tuiasi.ro \\ * Correspondence: calin.ciugudeanu@insta.utcluj.ro; Tel.: +40-752-193-890
}

Received: 30 September 2019; Accepted: 3 December 2019; Published: 12 December 2019

\begin{abstract}
For the next few years millions of fluorescent luminaires will become waste and will be replaced by light-emitting diodes-LED luminaires. According to the Cost European Cooperation in Science \& Technology Program, the next step will be shifting from sustainability to regeneration (enabling social and ecological systems to maintain a healthy state and to evolve); to reach this point, a is circular economy becomes necessary. The Technical University of Cluj-Napoca's Lighting Engineering Laboratory_LEL-is the main lighting independent consultant in Transylvania (the north-west region of Romania). For the Building Services Faculty, LEL adopted different energy efficient lighting solutions to replace existing fluorescent T8 luminaires. The best available techniques were evaluated over the last few years. Out of a range of different smart lighting control systems, LED were chosen and used for retrofitting the existing T8 luminaires or simply replacing them with new dedicated LED luminaires. The study analyzed five different lighting setups for upgrading the existing fluorescent T8 $2 * 36 \mathrm{~W}$ luminaires. One setup used T5 lamps and the others used retrofitted or dedicated LED lighting solutions. First the lighting quantities of each setup were evaluated under real and experimental conditions. Second, a programable power source was used for measuring power quality indicators corelated with the provided lighting outputs, under different voltage values and waveforms. For each lighting setup, an even and odd current harmonic limit check was performed in line with class C-lighting equipment, IEC 61000-3-2 requirements. A new energy efficiency and power quality indicator was proposed—the lighting apparent power density [VA/sq.m/100lx].
\end{abstract}

Keywords: lighting; LED; energy efficiency; retrofit luminaire; circular economy

\section{Introduction}

A circular economy is a regenerative system in which resource inputs and waste, emissions, and energy leakage are minimized by slowing, closing, and narrowing energy and material loops. This can be achieved through long-lasting design, maintenance, repair, reuse, remanufacturing, retrofit, recycling, and upcycling [1]. It contrasts with a linear economy, which is a "take, make, dispose" model of production [2]. As the world population is continuously growing, in order to ensure there are necessary resources in the near future for the year 2050, people will have to switch from a linear economy to a circular economy [3].

The EU in 2002 launched the first Waste of Electrical and Electronic Equipment (WEEE) directive [4,5] with the aim of collecting, recycling, and treating this waste [6]. Discharged lamps (fluorescent lamps, compact fluorescent lamps, high-pressure mercury and sodium lamps, and metal 
halide lamps) need to be collected separately, due to their mercury content (a hazardous and water contaminant material).

Worldwide, over the next few years, millions of fluorescent luminaires will become waste and will be replaced by LED luminaires. This has already occurred in some western and north European countries. Society is presently guided by a lighting linear economy-where all existing luminaires became waste and are replaced by new dedicated LED luminaires.

Luminaries are generally nonlinear loads connected to the low voltage AC distribution network. Some light sources, like fluorescent lamps and LEDs, require a power supply system (ballast or driver) to interface them with the electric network. Generally, the current waveform contains some amount of distortion, depending on the luminaries' technology [7].

However, as LEDs continue to replace incandescent and fluorescent lighting, there can be a significant impact on power distribution networks due to the non-linear nature of light emitting diodes. This paper will investigate the main power quality concerns arising from the use of LED lighting on our electrical networks. Further, it will also assess the impact of power quality disturbances on LED lighting technology [8].

The Technical University of Cluj-Napoca (UTC-N) for the years 2012, 2013, [9] and 2014, [10] financed an internal lighting efficiency project aiming to determine the actual energy consumption of university buildings as well as to identify the best techno-economical energy efficiency lighting solution available. Instead of simply replacing the existing luminaires, some retrofit lighting solutions were evaluated in order to reuse some parts of the existing T8 fluorescent luminaires.

A detailed measurement of the current consumption of the Faculty of Building Services-UTC-N, with a total area of 4775.98 sq. m was performed. Electricity and natural gas bills for the year 2012 were analyzed and the results can be seen in Table 1.

Table 1. Current annual energy consumption 2012-UTC-N-Faculty of Building Services.

\begin{tabular}{cccccccc}
\hline \multirow{2}{*}{$\begin{array}{c}\text { UTC-N } \\
\text { Faculty of } \\
\text { Building } \\
\text { Services }\end{array}$} & Area & \multicolumn{3}{c}{$\begin{array}{c}\text { ELECTRIC CONSUMPTION-0.155 } \\
\text { [euro/kWh] }\end{array}$} & \multicolumn{3}{c}{ NATURAL GAS } \\
\cline { 2 - 8 } & [sq. m] & [kWh/year] & [euro/year] & $\begin{array}{c}\text { [kWh/sq. } \\
\text { m/year] }\end{array}$ & [kWh/year] & [euro/year] & $\begin{array}{c}\text { [kWh/sq. } \\
\text { m/year] }\end{array}$ \\
\cline { 2 - 8 } & 4776 & 82,385 & 12,770 & 17.25 & 550,262 & 21,020 & 115.21 \\
\hline
\end{tabular}

A total energy (electrical and natural gas) consumption of $132.46[\mathrm{kWh} /(\mathrm{sq} . \mathrm{m} *$ year) $]$ was identified for the year 2012, based on the relevant utility bills [11].

The electricity consumption of the building was evaluated based on the readings recorded by an electronic meter. The hourly readings were recorded over a period of three years, namely 2014, 2015, and 2016. The total annual consumption rate was different during those years. Due to the installation of a new cooling system in the faculty main amphitheatre, there was an increase of 11,237 kWh/year, from 82,375 kWh/year in 2012 to 93,612 kWh/year in 2014.

Afterwards, a decrease from 93,612 kWh/year in 2014 to 86,190 kWh/year in 2015 and 68,901 kWh/year in 2016 was recorded (Figure 1), due to the new LED lighting system that was installed, which meant there was a general reduction of more than 25\% from 2014 to 2016.

Based on the global International Energy Agency (IEA) data, the lighting electricity consumption of commercial buildings in 2005 [12] was about $25 \mathrm{kWh} / \mathrm{sq}$. m /year for educational buildings. This represents about 19\% of the total UTC-N, Faculty of Building Services energy consumption for the year 2016 (129 kWh/sq. m/year).

Using the university adopted lighting retrofit solutions as case studies, circular economy aspects were identified [13]. For a LED retrofitted recessed luminaire T8 $4 \times 18 \mathrm{~W}$, a previous study [14], showed a major reduction of installed power as well as a correct lighting distribution, but also revealed some issues: lack of certification of the retrofit luminaire, the necessity of utilizing qualified personnel, high workforce costs, etc. 


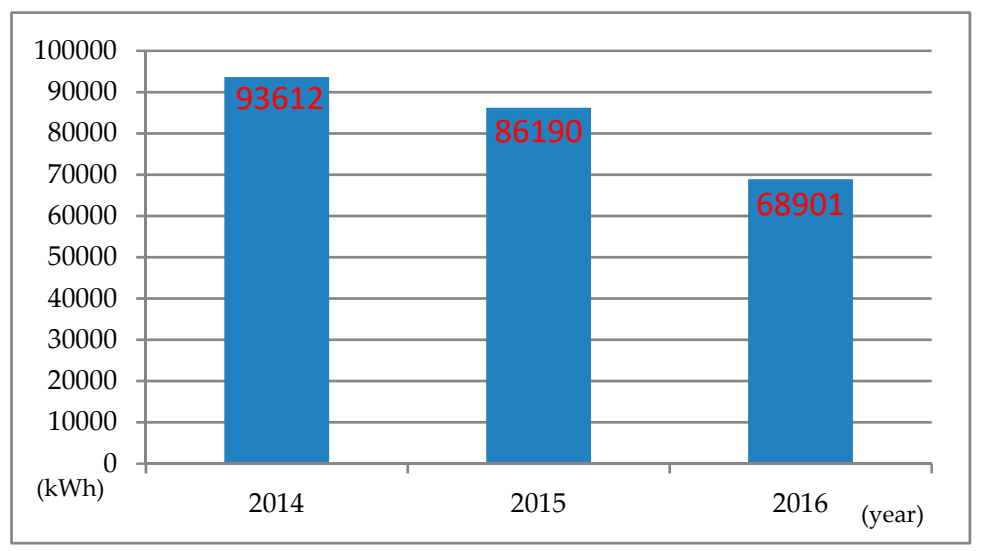

Figure 1. Technical University of Cluj-Napoca (UTC-N) Faculty of Building Services yearly electricity consumptions.

The present survey analyzes similar recessed luminaires using three different light sources: fluorescent T8, fluorescent T5, and LED. Different experimental setups were built up for measuring the illumination levels and the power quality indicators (power factor-PF, waveforms, total harmonic distortion-THD, etc.). As nonlinear loads, LEDs produce highly distorted currents. Many end users using LEDs for domestic, commercial, and industrial lighting could determine important power quality problems [15]. The harmonic absorptions of several types of lighting retrofit solutions were analyzed. The recorded harmonic absorption allows characterizing of the harmonic spectrum variability of the investigated luminaires. Using a programable power source, the power quality was evaluated under different voltage scenarios (voltage variations and waveforms). This paper details some new aspects such as:

1. The different proposed lighting setups including luminaires with similar lighting outputs and dimensions $(1200 \times 300 \mathrm{~mm})$, suitable for suspended modular ceiling. Special attention was paid to a LED lighting retrofit solution due to its ability to significantly reduce waste materials.

2. A new lighting energy efficiency indicator was proposed — the apparent power density-while some basic power quality indicators were considered as well.

3. The correlation between lighting outputs and power quality indicator alterations (the power supply voltage value and waveform) was assessed.

4. The harmonic limits of each lighting setup were evaluated according to class C-lighting equipment, IEC 61000-3-2 requirements. The harmonics limits were also calculated and compared with standard for different voltage values and waveform combinations $(207 \mathrm{~V}, 230 \mathrm{~V}, 253 \mathrm{~V}$, pure sine, clipped 10, and clipped 20).

\section{Materials and Methods}

Starting from a surveillance case study of fluorescent and LED luminaires made by LEL inside some of the university buildings, the present paper conducted some further investigations regarding five different lighting setups. The study is based on the very large present use of T8 fluorescent lamps in all existing administrative, educational, and office buildings in Europe and particularly in Romania. This study evaluates the measured lighting levels as well as the power quality implications regarding the proper operating and lighting quantities of the five proposed lighting setups presented in Table 2 and Figure 2.

The $\mathrm{A}, \mathrm{B}, \mathrm{D}$, and $\mathrm{E}$ setups used dedicated luminaires while $\mathrm{C}$ was a $\mathrm{T} 8$ retrofitted luminaire using LED. The A, B, C, and E setups used new lamps with less than 150 working hours. For the D lighting setup, the lamps could provide close to $500 \mathrm{~h}$ of operation. At the beginning, the lighting parameters (illumination, lighting distribution, and uniformity) were measured. Each different luminaire was tested inside an experimental setup. Some of them (A, B, D) were also evaluated and installed in 
a real environment (classrooms/laboratories). The second part of the study was dedicated to the measurement of the lighting setups power quality indices-PF, active/apparent power, waveforms, THD, etc. Using a programable power source, many different scenarios were analyzed, and some were detained: $230 \mathrm{~V} \pm 10 \%$ voltage variations $(207 \mathrm{~V}, 230 \mathrm{~V}, 253 \mathrm{~V})$, pure sine, clipped 10, and clipped 20 voltage waveforms-see Figure 3.

Table 2. Lighting setups—recessed $300 \mathrm{~mm} \times 1200 \mathrm{~mm}$ luminaires.

\begin{tabular}{cccccccc}
\hline Setup & Luminaires & Lamp & Dimmable & Power [W] & $\begin{array}{c}\text { Lighting } \\
\text { Output [lm] }\end{array}$ & Ballast & $\begin{array}{c}\text { Luminous } \\
\text { Efficacy [lm/W] }\end{array}$ \\
\hline A & dedicated T8 & T8 840 & NO & $2 \times 36$ & 5000 & electro-magnetic & 69.44 \\
B & dedicated T5 & T5 840 & NO & $2 \times 28$ & 5350 & electronic & 95.54 \\
C & retrofitted T8 & LED 864 & NO & $2 \times 18$ & 3000 & electronic & 83.33 \\
D & dedicated LED & LED 840 & NO & 37 & 4230 & electronic & 114.32 \\
E & dedicated LED & LED 840 & YES & 48 & 3840 & electronic & 80 \\
\hline
\end{tabular}
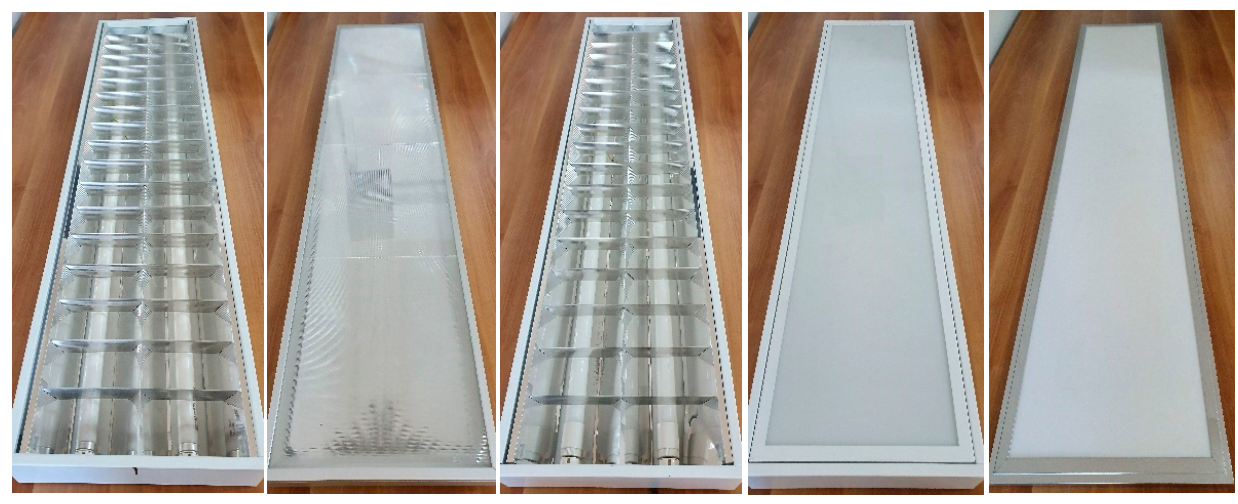

Figure 2. Luminaires A, B, C, D, E-from left to right.

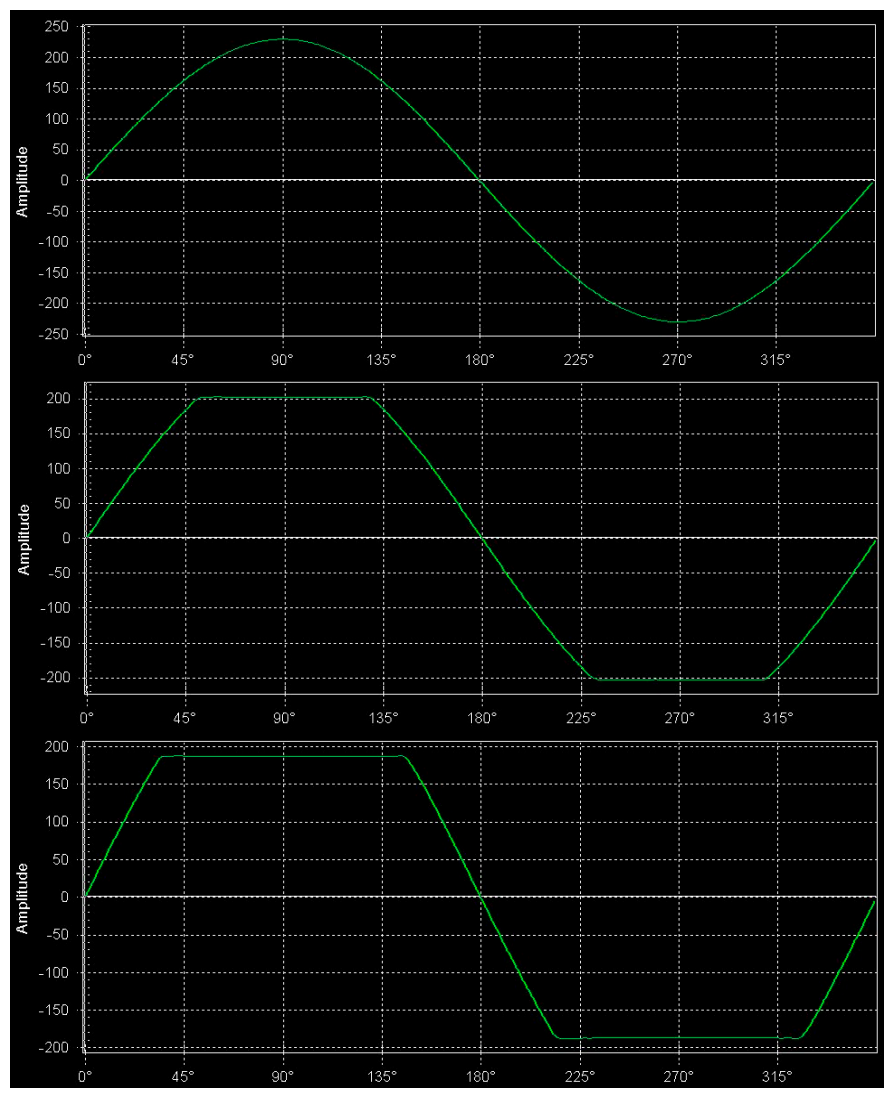

Figure 3. Voltage time domain reconstruction: $230 \mathrm{~V}$ pure sine, clipped 10 and clipped 20—up to down. 
For the A, B, and D setups, lighting setups measurements were performed under real conditions. The measured lighting levels on the work plane ( $0.8 \mathrm{~m}$ high above the floor), using a $0.6 \mathrm{~m} \times 0.8 \mathrm{~m}$ grid, were performed for recessed mounted luminaires in $4.2 \times 8.8 \mathrm{~m}$ wide room with a $3.15 \mathrm{~m}$ high ceiling. All the measurements were performed with a Testo 545 light meter and a permanently attached light sensor. Figure 4 presents the measured values on the work plane inside the classrooms using a $0.6 \mathrm{~m} \times$ $0.8 \mathrm{~m}$ grid. The measurements were obtained at night without daylight support. The walls and the ceiling were made of white painted plaster (reflection factor over $75 \%$ ), while the floor was a standard wood parquet floor (with a reflection factor over $40 \%$ ). The reflection factors were not measured but the same conditions were preserved for each field measurement lighting setup (including the same furniture) presented in Figure 4.
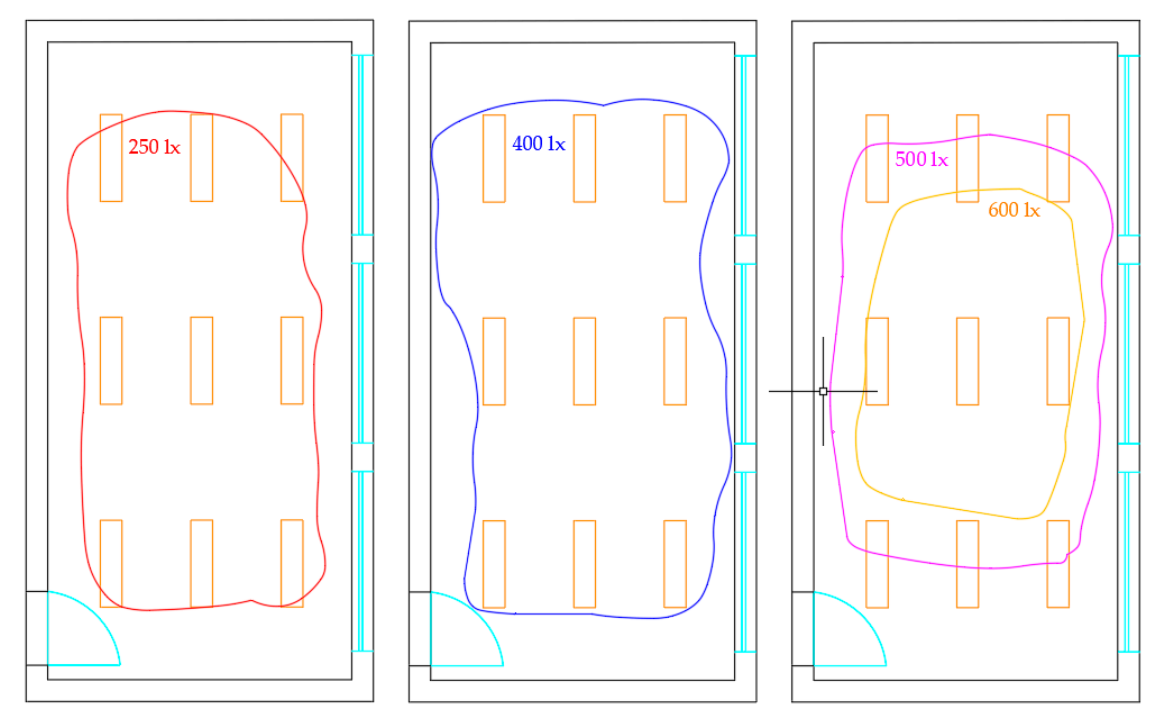

Figure 4. Field measured lighting isolux values on the work plane for the A, B, and D setups-from left to right.

The average, minimum, and maximum lighting levels are presented in Table 3. Only setup D faced complaints in SR EN 12646-1:2011-5.36.9 Educational Building [16] rooms for practical works and laboratories, regarding the average illuminance level not being above the requested $500 \mathrm{~lx}$ and 0.60 uniformity. The different lighting setups uniformities are almost the same-having values above 0.75. At the same time, the LED setup D uses less than half the energy of the setup A, providing more than double lighting the level.

Table 3. Classroom measured lighting levels on the work plane.

\begin{tabular}{lccc}
\hline \multicolumn{1}{c}{ MEASURED } & $\mathbf{2 \times \text { T8 36 W }}$ & $\mathbf{2 \times} \mathbf{~ T 5 ~ 2 8 ~ W ~}$ & LED 37 W \\
\hline Lighting setup & $\mathrm{A}$ & $\mathrm{B}$ & $\mathrm{D}$ \\
Minimum illumination level [lx] & 192 & 318 & 427 \\
Maximum illumination level [lx] & 306 & 470 & 673 \\
Average illumination level [lx] & 255 & 409 & 557 \\
Uniformity [min/average] & 0.75 & 0.78 & 0.77 \\
\hline
\end{tabular}

\section{Results}

During the present study, all the lighting setups were tested inside a $2 \mathrm{~m} \times 2.4 \mathrm{~m}$ wide experimental shed with a $2.5 \mathrm{~m}$ high ceiling. Figure 4 shows the different lighting levels in the work plane placed at $0.8 \mathrm{~m}$ above the floor level using a $0.4 \mathrm{~m} \times 0.4 \mathrm{~m}$ grid. The walls, ceiling, and floor were made of white painted wood (reflection factor over $65 \%$ ), with no windows or dedicated doors attached. The reflection factors were not measured but the same conditions were preserved for each lighting 
setup measurement. The results are presented in Figure 5 and summarized in Table 4. For each different luminaire and setup, the minimum, maximum, and average lighting levels are presented among the total power consumption and uniformity. The lighting active power density [W/sq. m/100lx] was calculated for each case.
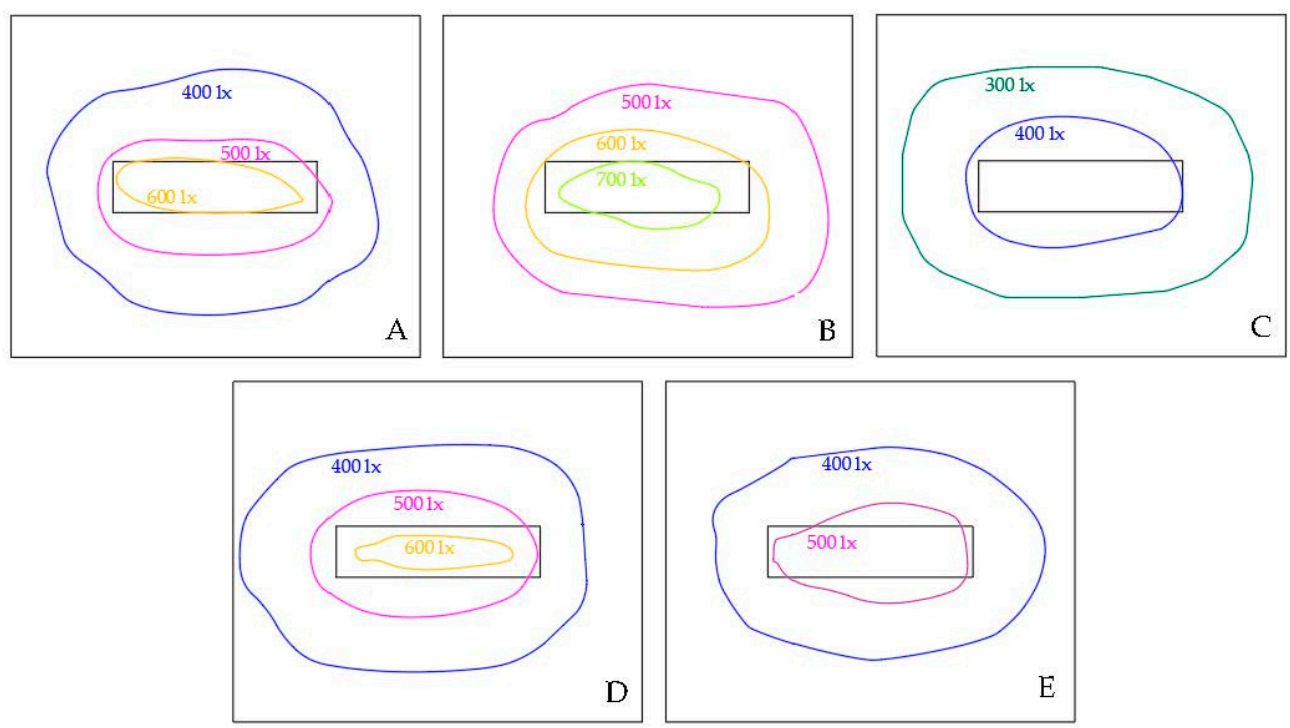

Figure 5. Experimental shed measured lighting values on the work plane for the A, B, C, D, E setups.

Table 4. Lighting measurements-experimental shed.

\begin{tabular}{lccccc}
\hline Lighting Setup & A & B & C & D & E \\
\hline Lamp & T8 $2 \times 36 \mathrm{~W}$ & $\mathrm{~T} 52 \times 28 \mathrm{~W}$ & LED 2 $\times 18 \mathrm{~W}$ & LED 37W & LED 48W \\
Total installed power [W] & 72 & 56 & 36 & 37 & 48 \\
Minimum illumination level [lx] & 341 & 400 & 273 & 350 & 325 \\
Maximum illumination level [lx] & 644 & 732 & 472 & 584 & 539 \\
Average illumination level [lx] & 474 & 570 & 361 & 459 & 430 \\
Uniformity [min/average] & 0.72 & 0.70 & 0.76 & 0.76 & 0.76 \\
Lighting active power density & 3.17 & 2.05 & 2.08 & 1.64 & 2.33 \\
[W/sqm/100lx]-2 $2.4=4.8$ sq. m & & & & & \\
\hline
\end{tabular}

The experimental shed measurements for the lighting setups A, B, C, D, E show the best average illumination level for the B setup (T5-2 $\times 28 \mathrm{~W}$ ) at around $570 \mathrm{~lx}$.

The uniformity (ratio between the minimum and average illumination) looks better for the LED setups with values over 0.75, complying at the same time with the SR EN 12646-1:2011 requirements [16] for office/educational rooms, with a requested uniformity over 0.60 .

Lighting active power density levels-an indicator of the luminaire energy efficiency capabilities-show the best value for the setup D using $36 \mathrm{~W}$ LED. The most inefficient setup, as expected, is setup A. Afterwards, the lighting active power density indicator is recalculated based on the real power quality measurements.

For the A, B, and D setups, measurements were performed in order to determine the different maintenance luminaire aspects. Additional lighting setups A', $\mathrm{B}^{\prime}, \mathrm{D}^{\prime}$ were created using dirty (installed and unmaintained for around two years) luminaires with new lamps. The measured values presented in Table 5 show illumination depreciation levels of about $10 \%$ for the T8 unsealed/open case luminaires. For the closed case $\mathrm{T} 5$, the illumination depreciation level drops to $5 \%$ to $8 \%$, while for the dedicated LED luminaires the illumination depreciation level reaches $2 \%$ to $5 \%$. The uniformity values are similar with a very small improvement for the D lighting setup. 
Table 5. Clean versus dirty luminaires—lighting measurements.

\begin{tabular}{|c|c|c|c|c|c|c|}
\hline Lighting Setup & A & $\mathbf{A}^{\prime}$ & B & $\mathbf{B}^{\prime}$ & D & $\mathrm{D}^{\prime}$ \\
\hline Luminaire—clean/dirty & clean & dirty & clean & dirty & clean & dirty \\
\hline Minimum illumination level [lx] & 341 & 308 & 400 & 380 & 350 & 333 \\
\hline Depreciation [\%] & \multicolumn{2}{|c|}{$9.68 \%$} & \multicolumn{2}{|c|}{$5.00 \%$} & \multicolumn{2}{|c|}{$4.86 \%$} \\
\hline Maximum illumination level [lx] & 644 & 582 & 732 & 673 & 584 & 565 \\
\hline Depreciation [\%] & \multicolumn{2}{|c|}{$9.63 \%$} & \multicolumn{2}{|c|}{$8.06 \%$} & \multicolumn{2}{|c|}{$3.25 \%$} \\
\hline Average illumination level [lx] & 474 & 430 & 570 & 541 & 459 & 446 \\
\hline Depreciation [\%] & \multicolumn{2}{|c|}{$9.28 \%$} & \multicolumn{2}{|c|}{$5.09 \%$} & \multicolumn{2}{|c|}{$2.83 \%$} \\
\hline Uniformity [min/average] & 0.72 & 0.72 & 0.70 & 0.70 & 0.76 & 0.75 \\
\hline
\end{tabular}

The power quality indicators were tracked down, measured, and sometimes intentionally altered for each lighting setup using the $5 \mathrm{kVA}$ AC Power Source-California Instruments model 5001. The maximum illumination level was also measured right under the luminaire at a $1.7 \mathrm{~m}$ distance, similar to the one from the experimental shed (between the luminaire and the working plane at 0.8-2.5 m). For the illumination measurement, a $1.6 \mathrm{~m} \times 0.6 \mathrm{~m}$ and $1.7 \mathrm{~m}$ height cardboard box was used-Figure 6 . The recordings were made using the same Testo 545 light meter. Some of the results are presented later in this paper.

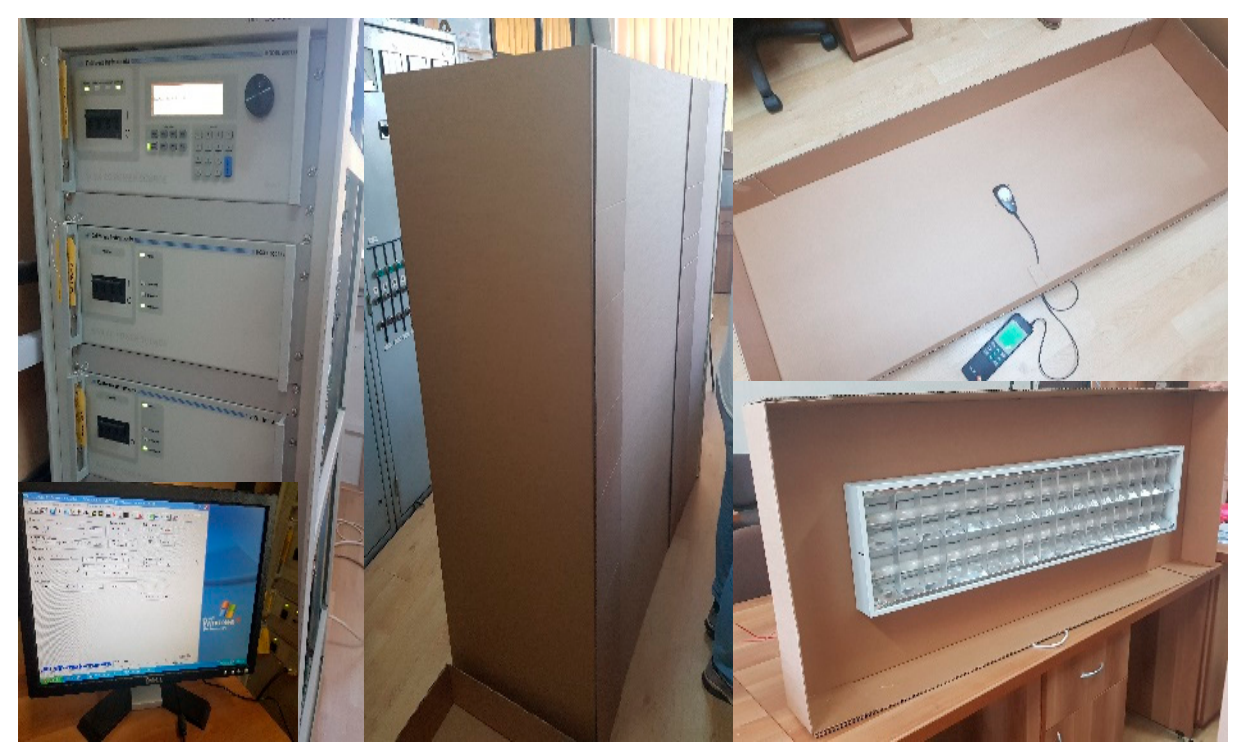

Figure 6. Energy quality/lighting level survey for the A, B, C, D, and E lighting setups.

The general electric measurements are presented in Table 6 for all the lighting setups supplied with a constant $50 \mathrm{~Hz}, 230 \mathrm{~V}$ pure sine voltage - the A, B, C, D, and E. Additionally the voltage was clipped 10 - the $\mathrm{A}^{*}, \mathrm{~B}^{*}, \mathrm{C}^{*}, \mathrm{D}^{*}$, and $\mathrm{E}^{*}$ setups and then clipped 20 - the $\mathrm{A}^{* *}, \mathrm{~B}^{* *}, \mathrm{C}^{* *}, \mathrm{D}^{* *}$, and $\mathrm{E}^{* *}$ setups.

There is a gap between the total installed active power (Table 4) and the measured power (Table 6) because of the magnetic ballasts/electronic drivers power losses. In all the cases except for the B setup (56 W installed; $51 \mathrm{~W}$ measured), the measured power is bigger than the installed nominal one. The biggest difference is for the A lighting setup (magnetic ballast) where the measured is $12 \mathrm{~W}$ over the installed power ( $72 \mathrm{~W}$ installed; $84 \mathrm{~W}$ measured). Even though all the power quality aspects are generally deteriorating while altering the voltage waveform to clipped 10 and then 20 , the $\mathrm{C}$ and $\mathrm{E}$ lighting setups have a very low power factor and consequently a high value apparent power. 
Table 6. Power quality measurements—A, B, C, D, and E setups—-230 V—pure sine, clipped 10, and clipped 20.

\begin{tabular}{|c|c|c|c|c|c|c|c|c|c|c|c|c|c|c|c|}
\hline Lighting Setup & A & $\mathrm{A}^{*}$ & $A^{* *}$ & B & B* $^{*}$ & $\mathbf{B}^{* *}$ & C & $C^{*}$ & $C^{* *}$ & D & $D^{*}$ & $\mathrm{D}^{* *}$ & $\mathbf{E}$ & $\mathrm{E}^{*}$ & $E^{* *}$ \\
\hline Voltage [V] & 230 & 230 & 230 & 230 & 230 & 230 & 230 & 230 & 230 & 230 & 230 & 230 & 230 & 230 & 230 \\
\hline Current [A] & 0.40 & 0.41 & 0.47 & 0.24 & 0.24 & 0.24 & 0.57 & 0.62 & 0.71 & 0.19 & 0.19 & 0.20 & 0.72 & 0.58 & 0.51 \\
\hline Power [W] & 84 & 82 & 78 & 51 & 51 & 52 & 38 & 39 & 39 & 40 & 40 & 40 & 52 & 52 & 52 \\
\hline Power factor PF & 0.91 & 0.86 & 0.72 & 0.91 & 0.92 & 0.93 & 0.30 & 0.28 & 0.24 & 0.91 & 0.90 & 0.86 & 0.32 & 0.39 & 0.45 \\
\hline Peak current [A] & 2.23 & 1.06 & 1.18 & 0.53 & 0.49 & 0.50 & 1.05 & 1.19 & 1.48 & 0.45 & 0.43 & 0.47 & 5.38 & 4.21 & 3.66 \\
\hline Crest Factor & 1.67 & 2.54 & 2.52 & 2.07 & 1.98 & 1.90 & 1.84 & 1.85 & 2.04 & 2.07 & 2.15 & 2.22 & 7.47 & 7.29 & 6.93 \\
\hline THDv [\%] & 0.20 & 10.07 & 20.15 & 0.21 & 10.07 & 20.17 & 0.20 & 10.10 & 20.15 & 0.21 & 10.08 & 20.12 & 0.33 & 10.06 & 20.12 \\
\hline THDi [\%] & 18.55 & 40.10 & 65.06 & 7.53 & 10.99 & 21.67 & 14.78 & 43.15 & 63.87 & 9.40 & 13.12 & 22.96 & 92.04 & 88.14 & 84.86 \\
\hline
\end{tabular}

The electronic ballasts generally managed to provide a constant lighting output. The lighting setups were also tested with $a+/-10 \%$ voltage variation. Just the setup A with electromagnetic ballast presented an important variation (Table 7), while the other ones with electronic ballasts managed to keep the luminaires lighting output constant. For the $\mathrm{A}, \mathrm{A}^{*}$, and $\mathrm{A}^{* *}$ lighting setups, the biggest recorded illumination level was $694 \mathrm{~lx}$ for the pure sine $253 \mathrm{~V}$, while the smallest of $529 \mathrm{~lx}$ was for the 207 V clipped 20.

Table 7. Illumination versus voltage variation and waveform.

\begin{tabular}{lccc}
\hline Voltage & \multicolumn{1}{c}{ Maximum Illumination Level Measured Inside the Box [1x] } \\
\hline Lighting & $\mathrm{A}$ & $\mathrm{A}^{*}$ & $\mathrm{~A}^{* *}$ \\
setup & 573 & 551 & 529 \\
$207 \mathrm{~V}$ & 610 & 598 & 581 \\
$230 \mathrm{~V}$ & 694 & 681 & 665 \\
$253 \mathrm{~V}$ & &
\end{tabular}

A $10 \%$ increased nominal voltage $(253 \mathrm{~V})$ showed a $14 \%$ increased lighting level on average. A $10 \%$ decrease of the nominal voltage $(207 \mathrm{~V})$ revealed an average depreciation lighting level of $7.6 \%$. A modified voltage waveform from pure sine to clipped 10 provided a depreciation lighting level of $2.5 \%$ while from pure sine to clipped 20 , the lighting depreciation reached $5.5 \%$.

The recorded waveforms both for voltage and current involving each lighting setup and the pure sine, clipped 10, and clipped 20 voltage scenarios are presented in Figures 7-11.

The measured Total Harmonic Distortion (THD) both for voltage $\mathrm{THDV}$ and current $\mathrm{THD}_{\mathrm{I}}$ are presented in the last lanes of Table $6 . \mathrm{THD}_{\mathrm{I}}$ is a measurement of the harmonic distortion present and is defined as the ratio of the sum of the powers of all harmonic components to the power of the fundamental frequency. For the pure sine scenario, the lowest $\mathrm{THD}_{\mathrm{I}}$ was recorded for the $\mathrm{B}$ and $\mathrm{D}$ lighting setups with values under $10 \%$. The lighting setup $\mathrm{E}$ recorded the highest $\mathrm{THD}_{\mathrm{I}}$ values for pure sine, clipped 10 and clipped 20 scenarios by far. Besides setup E, for a pure sine voltage the second highest $T H D_{I}$ was recorded for setup $A$ while for clipped 10 the second $T H D_{I}$ was setup $C$ and for clipped 20 the second $\mathrm{THD}_{\mathrm{I}}$ was setup A.

While the relevant standards and requirements applicable to the lighting projects are considered, distributors should also consider operating requirements and specific circumstances for their networks [17]. The authorization to connect equipment to the low voltage system depends on the levels of disturbance caused by the equipment [18]. IEC61000-3-2 [19] specifies the limits for harmonic currents of equipment connected to low voltage distribution networks. This standard assesses and sets the limits for equipment with the input current $\leq 16 \mathrm{~A}$ per phase and covers both quasi-stationary harmonics and fluctuating harmonics. According to this standard, equipment is classified into four classes in which class $C$ is lighting equipment including dimming devices $[19,20]$.

The harmonic current limit for class $C$ equipment is shown in Table 8 in which $\lambda$ is power factor of the equipment. It should be taken into consideration that these limits are for individual harmonics 
and do not specify total harmonic distortion (THD) [21]. Only 2nd even harmonic and odd-order harmonics are shown because the rest of the even-order harmonics are almost zero.

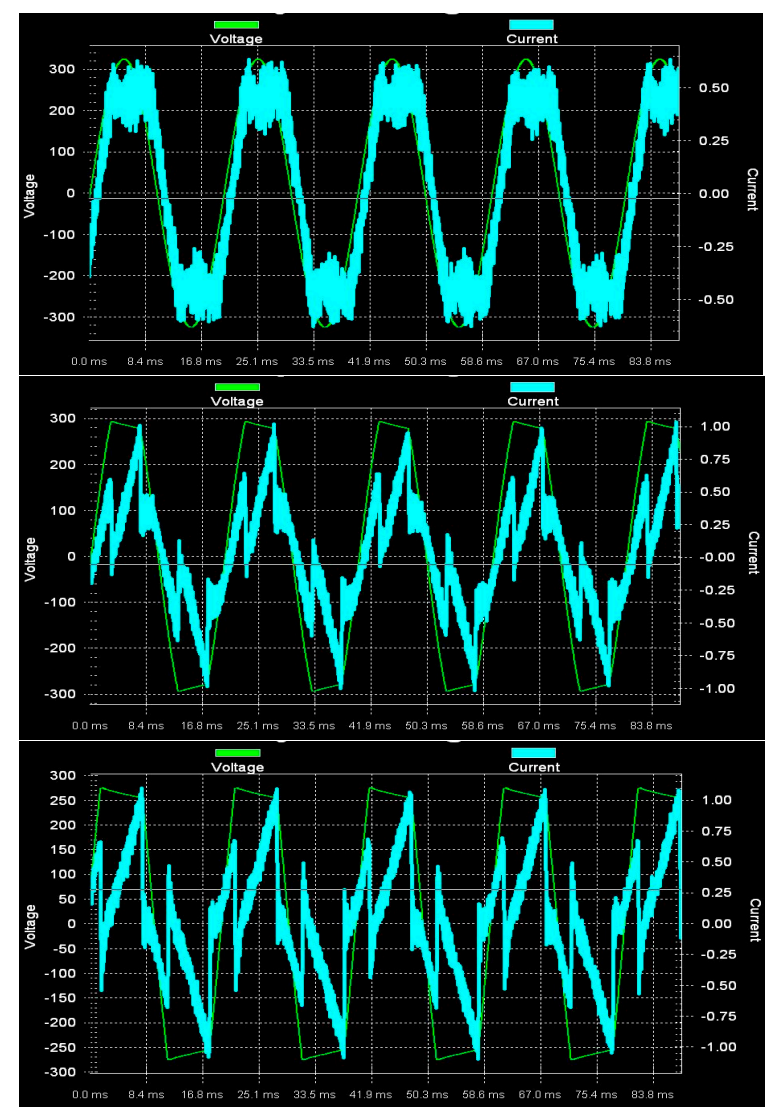

Figure 7. Voltage and current waveforms- $\mathrm{A}, \mathrm{A}^{*}$, and $\mathrm{A}^{* *}$ lighting setups.

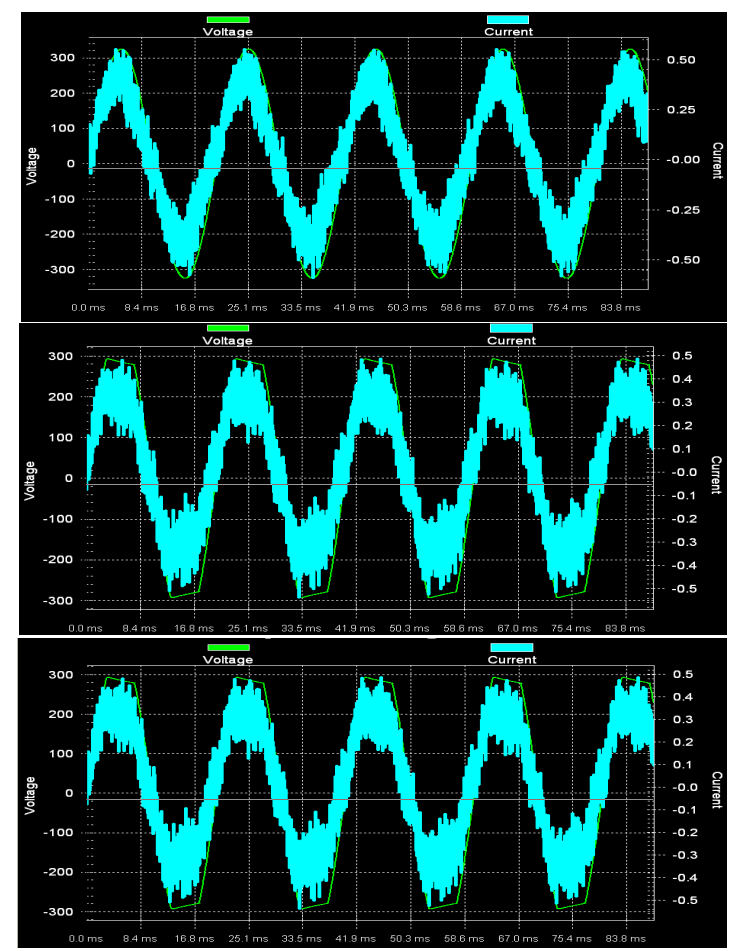

Figure 8. Voltage and current waveforms $-\mathrm{B}, \mathrm{B}^{*}$, and $\mathrm{B}^{* *}$ lighting setups. 


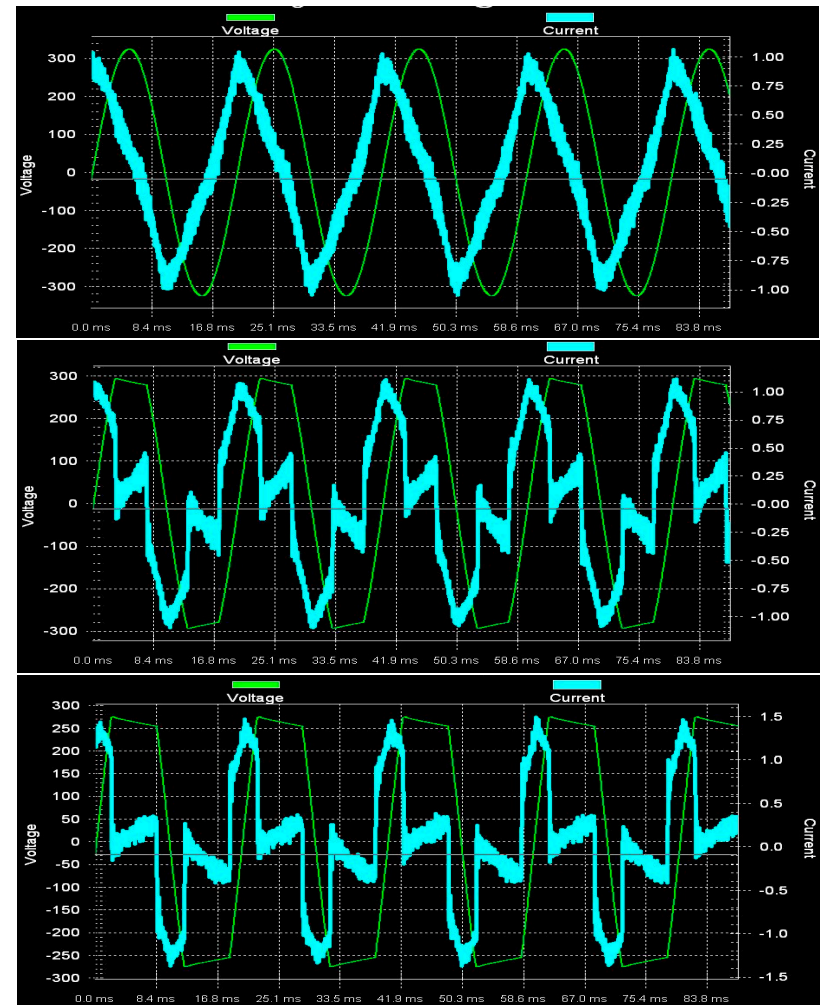

Figure 9. Voltage and current waveforms $-C, C^{*}$, and $C^{* *}$ lighting setups.
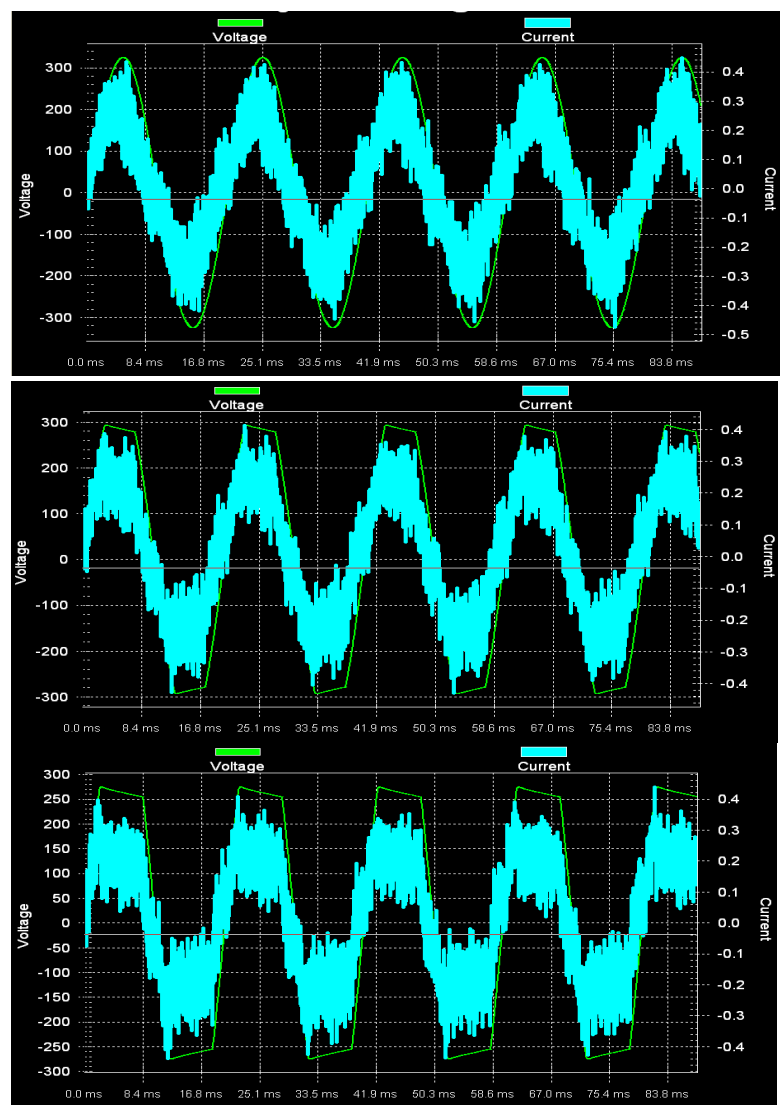

Figure 10. Voltage and current waveforms-D, $\mathrm{D}^{*}$, and $\mathrm{D}^{* *}$ lighting setups. 

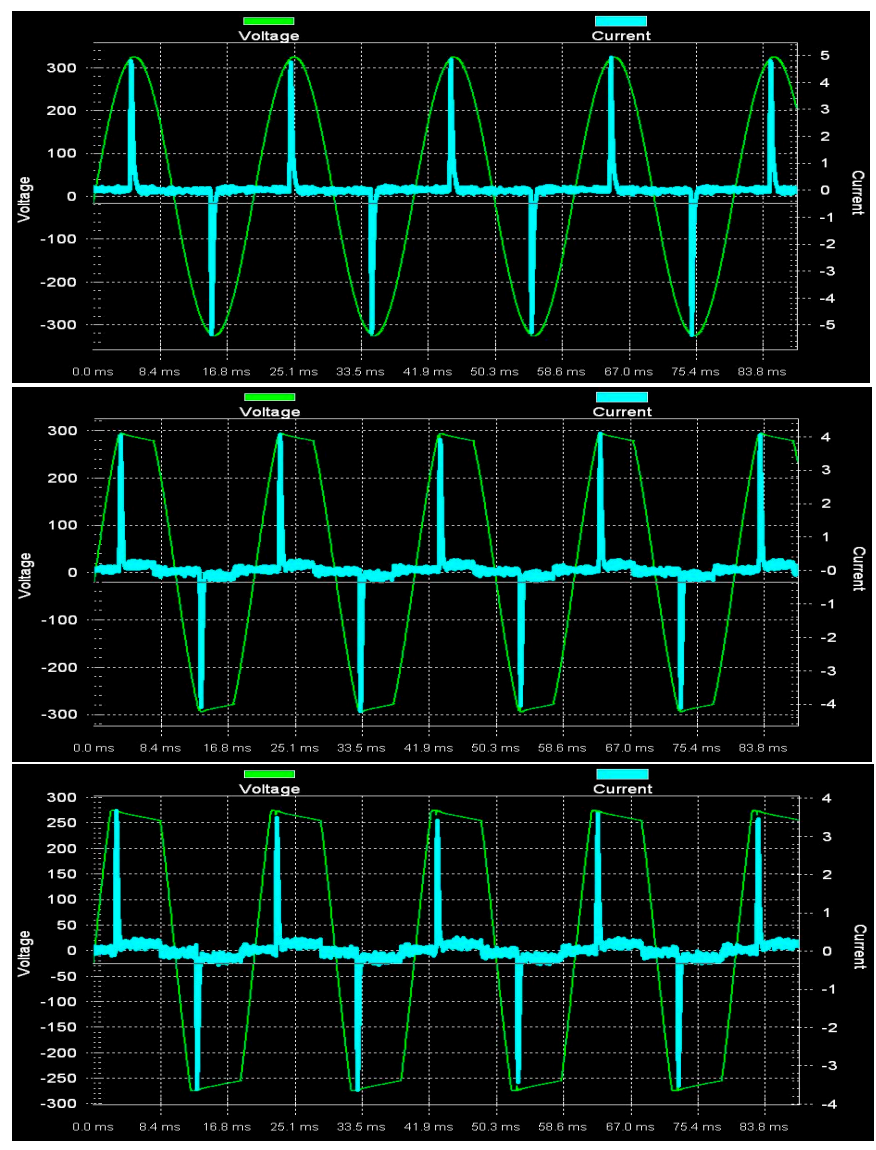

Figure 11. Voltage and current waveforms- $\mathrm{E}, \mathrm{E}^{*}$ and $\mathrm{E}^{* *}$ lighting setup.

Table 8. Harmonic limits for class C equipment [19].

\begin{tabular}{cc}
\hline Harmonic Order $n$ & $\begin{array}{c}\text { Maximum Permissible Harmonic Current Expressed as a } \\
\text { Percentage of the Input Current at the Fundamental Frequency } \%\end{array}$ \\
\hline 2 & 2 \\
3 & $30 \times \lambda$ \\
5 & 10 \\
7 & 7 \\
9 & 5 \\
$11 \leq \mathrm{n} \leq 39$ & 3 \\
\hline
\end{tabular}

For each lighting setup, an even (2) and odd (3-39) current harmonic limit check was performed according to IEC 61000-3-2 [19]. The results are described in Table 9. For the pure sine wave scenario, the A, B, and D setups pass the verification and were under the IEC class C limits for all the harmonics. Setup C overpassed the limit with $164 \%$ for the third order harmonics, while for the E setup, the limits were exceeded in all the odd harmonics, in some cases even with more than $2000 \%$. Here again the economic/budget LED lighting retrofit solutions $C$ and $E$ showed a major limitation, while dedicated luminaires passed the test. The same harmonic limits check was also performed for clipped 10 and 20 voltage scenarios. For all the lighting setups, the limits began in some cases to be exceeded for the clipped 10 voltage scenario and even more so for the clipped 20 voltage scenarios. For the clipped 10 voltage scenarios, only the lighting setup $B^{*}$ passed the test under the IEC limits for all harmonics. For the clipped 20 voltage scenario none of the lighting setups passed the test, although the $\mathrm{B}^{* *}$ setup performed better than the others (only harmonic 9 passed the IEC limit). The tests performed with the clipped voltage 10 and 20 did not represent hypothetical situations. They can often occur in 
practice. Thus, several UPSs or inverters present quite high $\mathrm{THD}_{\mathrm{V}}$ values. Consequently, these tests are important in order to assess the immunity of the setups.

Table 9. Measured current harmonic limits for class C equipment for the A, B, C, D, E setups-230 V-pure sine, clipped 10, and clipped 20.

\begin{tabular}{|c|c|c|c|c|c|c|c|c|c|c|c|c|c|c|c|}
\hline & \multicolumn{5}{|c|}{ Pure Sine } & \multicolumn{5}{|c|}{ Clipped 10} & \multicolumn{5}{|c|}{ Clipped 20} \\
\hline & A & B & $\mathrm{C}$ & D & E & $\mathbf{A}^{*}$ & B $^{*}$ & $\mathrm{C}^{*}$ & $\mathrm{D}^{*}$ & $\mathrm{E}^{*}$ & $\mathbf{A}^{* *}$ & $\mathrm{~B}^{* *}$ & $\mathrm{C}^{* *}$ & $D^{* *}$ & $\mathrm{E}^{* *}$ \\
\hline No. & \multicolumn{5}{|c|}{$\%$ of Limit } & \multicolumn{5}{|c|}{$\%$ of Limit } & \multicolumn{5}{|c|}{$\%$ of Limit } \\
\hline 2 & 41 & 19 & 0 & 54 & 107 & 28 & 18 & 18 & 54 & 62 & 30 & 37 & 112 & 0 & 63 \\
\hline 3 & 82 & 18 & 165 & 24 & 1011 & 112 & 25 & 520 & 25 & 494 & 356 & 72 & 10 & 94 & 310 \\
\hline 5 & 36 & 23 & 27 & 32 & 940 & 293 & 66 & 147 & 98 & 642 & 127 & 5 & 155 & O & 598 \\
\hline 7 & 47 & 44 & 2 & 54 & 1288 & 28 & 37 & 29 & 54 & 935 & 422 & 89 & 261 & 143 & 705 \\
\hline 9 & 27 & 47 & 2 & 65 & 1726 & 346 & 15 & 247 & 0 & 1177 & 500 & 103 & 3 & 156 & 1079 \\
\hline 11 & 27 & 52 & 18 & 54 & 2692 & 140 & 98 & 60 & 109 & 2099 & 141 & 61 & 1 & 37 & 1674 \\
\hline 13 & 18 & 65 & 6 & 54 & 2521 & 317 & 74 & 212 & 109 & 1866 & 693 & 0 & 4 & 37 & 1632 \\
\hline 15 & 9 & 26 & 12 & 0 & 2322 & 223 & 25 & 151 & 0 & 1893 & 331 & 25 & 211 & 0 & 1618 \\
\hline 17 & 9 & 26 & 6 & 18 & 2137 & 149 & 37 & 115 & 0 & 1770 & 311 & 74 & 187 & 93 & 1464 \\
\hline 19 & 0 & 13 & 6 & 18 & 1937 & 223 & 37 & 145 & 36 & 1632 & 452 & 74 & 274 & 93 & 1492 \\
\hline 21 & 9 & 0 & 6 & 36 & 1766 & 37 & 0 & 24 & 0 & 1605 & 40 & 37 & 25 & 37 & 1297 \\
\hline 23 & 0 & 13 & 6 & 36 & 1595 & 186 & 12 & 133 & 54 & 1413 & 331 & 0 & 211 & 19 & 1311 \\
\hline 25 & 0 & 0 & 0 & 18 & 1453 & 47 & 0 & 24 & 36 & 1385 & 251 & 12 & 168 & 37 & 1116 \\
\hline 27 & 0 & 13 & 0 & 18 & 1325 & 149 & 0 & 103 & 36 & 1248 & 90 & 12 & 56 & 19 & 1130 \\
\hline 29 & 0 & 13 & 0 & 18 & 1211 & 93 & 12 & 61 & 36 & 1139 & 271 & 25 & 180 & 37 & 962 \\
\hline 31 & 0 & 0 & 6 & 0 & 1111 & 84 & 12 & 60 & 18 & 1084 & 110 & 0 & 68 & 19 & 934 \\
\hline 33 & 0 & 13 & 0 & 18 & 1011 & 112 & 12 & 85 & 36 & 933 & 161 & 12 & 106 & 37 & 837 \\
\hline 35 & 0 & 0 & 0 & 0 & 912 & 28 & 12 & 24 & 18 & 905 & 221 & 25 & 143 & 56 & 767 \\
\hline 37 & 0 & 0 & 0 & 18 & 826 & 112 & 12 & 79 & 18 & 796 & 0 & 0 & 0 & 19 & 725 \\
\hline 39 & 0 & 0 & 0 & 0 & 741 & 9 & 0 & 12 & 0 & 741 & 201 & 0 & 124 & 0 & 614 \\
\hline
\end{tabular}

Table 10 shows the different power measurements recorded in terms of nominal lamp power, active power, apparent power, power factor, and average illumination level as well as the calculated installed, active, and apparent power density.

Table 10. Lighting setup installed, active, and apparent power density.

\begin{tabular}{|c|c|c|c|c|c|c|}
\hline Lighting Setup & A & B & $\mathrm{C}$ & $\mathrm{C} 1$ & $\mathbf{D}$ & $\mathbf{E}$ \\
\hline Installed nominal power [W] & 72 & 56 & 36 & 36 & 37 & 48 \\
\hline Measured active power [W] & 84 & 51 & 38 & 38 & 40 & 52 \\
\hline Measured apparent power [VA] & 92 & 57 & 131 & 72 & 44 & 165 \\
\hline Average illumination level $[\mathrm{lx}]$ measured inside the shed & 474 & 570 & 361 & 369 & 459 & 430 \\
\hline Lighting installed power density $[\mathrm{W} / \mathrm{sq} \cdot \mathrm{m} / 100 \mathrm{~lx}]-2 \times 2.4=4.8 \mathrm{sq} \cdot \mathrm{m}$ & 3.17 & 2.05 & 2.08 & 2.03 & 1.68 & 2.33 \\
\hline Lighting active power density [W/sq.m/100lx] $-2 \times 2.4=4.8$ sq.m & 3.69 & 1.86 & 2.19 & 2.15 & 1.82 & 2.52 \\
\hline Lighting apparent power density [VA/sq.m/100lx] $-2 \times 2.4=4.8$ sq.m & 4.05 & 2.08 & 7.55 & 4.07 & 2.00 & 8.00 \\
\hline
\end{tabular}

For the new $\mathrm{C}$ lighting setup, a new $\mathrm{C} 1$ setup was introduced because of the manufacturers and users installation guides about the simple replacing of the $\mathrm{T} 836 \mathrm{~W}$ fluorescent lamps with the LED $18 \mathrm{~W}$ tube while just removing the starters-setup C. Taking the recorded measurements into consideration, a better retrofit solution would be to remove all the specific T8 luminaires equipment such as starters, ballast, a compensator, etc.-setup C1. This last solution gives a $45 \%$ apparent power reduction (C-from 131 VA to $\mathrm{C} 1-72 \mathrm{VA}$ ) and improved lighting levels results, compared with the $\mathrm{C}$ setup. It is, however, true that the $\mathrm{C} 1$ setup needs a more specialized worktime (rewiring and extracting the specific T8 equipment).

Table 10 shows the different installed, active and apparent power densities calculated based on the power measurements. The difference between the three power densities is not so big for the A, B, and $\mathrm{D}$ lighting setups while for the $\mathrm{C}$ and $\mathrm{E}$, the apparent density is around 3.5 times bigger than the installed power density. 


\section{Conclusions}

Even though in some cases the retrofit solutions of the existing T8 luminaires with LED lamps seems to be the best solution for a future lighting circular economy, there are still many problems regarding the power quality aspects. The retrofit process itself is a difficult one, takes a lot of time, and needs to be done by a more highly trained lighting endorser. The achieved luminaire characteristics are also far from those of the dedicated new LED luminaires in terms of efficiency, maintenance, design, etc. But this reuse approach is a first step to a circular lighting economy. Similar studies [15] show a reused materials percentage of over $60 \%$ from the total mass of a dedicated T8 luminaires. The equivalent $\mathrm{CO}_{2}$ savings of about $9 \mathrm{~kg} \mathrm{CO}$ eq could be achieved by reusing T8 luminaires components (steel case, aluminum reflector, copper cables etc.), taking into consideration the $\mathrm{CO}_{2}$ emission factors from reference [22].

While the new retrofit lighting systems can use modern control systems and have the ability to be dimmed, in some cases they also lose the CE mark and the EMC certifications (setup C and E). In some cases, when replacing a component with a $C E$ marked one in a CE marked luminaire can result in a luminaire that does not meet the $\mathrm{CE}$ requirements. The second part of the study involving power quality aspects reveals major problems regarding the low cost retrofit lighting solution setup $C$ or even some budget dedicated dimmable LED luminaires, which is setup E. Therefore, the selection of the proper lighting gear is crucial during the retrofit design phase, not only for satisfying the requirements imposed by regulations on average illuminance and uniformity, but also for their energy performance and power quality.

The global environmental impact for incandescent, CFL, and LED lamps presented in reference [23] shows that the major impact is owned by the utilization stage, between $83.9 \%$ incandescent, $73.0 \%$ LED, and $70.9 \%$ CFL. The raw materials, production, transport, and end life stages are responsible for less than $30 \%$ of the global environmental impact of the lamps, even if this value goes higher for the new LED lamps. This utilization stage is mainly connected with the luminaire efficiency, but not necessarily in terms of a strict luminous efficacy but rather the ability of the luminaire to deliver a certain illuminance over the work plane, while also taking into consideration the power quality aspects. The tested luminaires show poor power quality indicators for some market refurbishment LED solutions (setup C) and even for dedicated LED dimmable luminaires (setup E). Similar studies marked the same problems. The [24] results obtained from the power quality meter and oscilloscope indicated that LEDs with external drivers caused severe harmonic distortion and power quality because the external driver can drive multiple lamps per driver. Large dispersion and high values of flicker perception have been observed for the modern lighting technologies using LED, even if they have a lower sensitivity than the incandescent lamps [25].

Regarding the lighting characteristics, compared with other similar studies $[7,8]$, the electronic ballasts were able to provide a constant lighting output in every case (even for a larger voltage range, between 150 and $270 \mathrm{~V}$ ). The setup A was the most lighting sensitive to power quality changes-lighting output variation presented in Table 7 -with a maximum of $10 \%$ lighting output variation corelated with voltage values variation and $5.5 \%$ for the different assessed waveforms.

In terms of power quality-the dedicated luminaires operated much more effectively and passed the IEC requirements for a pure sinewave voltage (A, B, D). Setup C and E were the worst settings here and the IEC 61000-3-2, class $C$ indicated harmonic limits were exceeded even for a $230 \mathrm{~V}$ pure sine waveform voltage. If the retrofit solution is the best one regarding time spending and waste management, then replacing a CE certified luminaire equipment with another $C E$ certified one can result in a non-CE luminaire.

For future work, these studies should be repeated for a wider group of LED tube lamps available on the market as fluorescent T8 luminaire retrofit solutions. In order to investigate the effectiveness of the present study results, the most appropriate and low waste lighting retrofit solution of the T8 luminaires should be identified. 
Author Contributions: Conceptualization, C.C. and D.B.; Methodology, C.C.; Validation, C.C. and M.B.; Formal Analysis, M.B.; Investigation, C.C.; Resources, A.C.; Data Curation, C.C.; Writing-Original Draft Preparation, C.C.; Writing-Review \& Editing, C.C. and M.B.; Visualization, M.B. and C.D.G.; Supervision, C.C.; Project Administration, C.C.; Funding Acquisition, C.C.

Funding: This research received no external funding.

Acknowledgments: Technical University of Cluj-Napoca, Building Services Faculty-for the financial and administrative support.

Conflicts of Interest: The authors declare no conflict of interest. The funders had no role in the design of the study; in the collection, analyses, or interpretation of data; in the writing of the manuscript, and in the decision to publish the results.

\section{References}

1. Geissdoerfer, M.; Savaget, P.; Bocken, N.; Bocken, N.M.P.; Hultink, E.J. The Circular Economy-A new sustainability paradigm? J. Clean. Prod. 2017, 143, 757-768. [CrossRef]

2. MacArthur, E. Towards the Circular Economy: An Economic and Business Rationale for an Accelerated Transition. Available online: https://www.ellenmacarthurfoundation.org/assets/downloads/publications/ Ellen-MacArthur-Foundation-Towards-the-Circular-Economy-vol.1.pdf (accessed on 9 September 2018).

3. Government of the Netherlands. From a Linear to a Circular Economy. Available online: https://www. government.nl/topics/circular-economy/from-a-linear-to-a-circular-economy (accessed on 9 September 2018).

4. Directive 2002/96/EC on waste electrical and electronic equipment (WEEE). Official J. EU L37, 2003, $24-38$. Available online: https:/eur-lex.europa.eu/resource.html?uri=cellar:ac89e64f-a4a5-4c13-8d96-1fd1d6bcaa49. 0004.02/DOC_1\&format=PDF (accessed on 30 October 2019).

5. Directive 2012/19/EC on waste electrical and electronic equipment (WEEE). Official J. EU L197, $2012,38-71$. Available online: https://eur-lex.europa.eu/LexUriServ/LexUriServ.do?uri=OJ:L:2012:197:0038:0071:en:PDF (accessed on 30 October 2019).

6. Marc, G. The Challenges and Opportunities for Lamp Recycling in the Next Five Years. In Proceedings of the 17th International Electronics Recycling Congress IERC 2018, Salzburg, Austria, 17-18 January 2018.

7. Akila, A.A.; Youssef, K.; Yassin, I. Harmonics Monitoring Survey on LED Lamps. Renew. Energy Sustain. Dev. 2017, 3. [CrossRef]

8. Bolduc, R. Impact of LED Lighting on Power Quality. Schneider Electric White Paper. 2017. Available online: https://www.se.com/ww/en/download/document/998-2095-10-07-17AR0_EN/ (accessed on 9 October 2019).

9. Ceclan, A. Innovative Research Tools for an Efficient Energy University. UTC-N Project no. 23990/2013, Cluj-Napoca. 2013.

10. Ciugudeanu, C. Energy_Efficient Technologies for a Green University. UTC-N Project no. 29223/2014, Cluj-Napoca, 2014. Available online: https://research.utcluj.ro/tl_files/research/Presentations/Conferinta\% 20Cercetarii\%202015/prezentare_INST_2015.pdf (accessed on 9 October 2019).

11. Beu, D.; Ciugudeanu, C.; Ceclan, A. Energy Efficient Lighting in University Buildings. In Proceedings of the Lux Europa 2017, Ljubljana, Slovenia, 18-20 September 2017; pp. 142-146.

12. International Energy Agency (IEA). Light's Labour's Lost; IEA Publications: Paris, France, 29 June 2006.

13. Scottish Engineering Hall of Fame. Available online: http://www.engineeringhalloffame.org/profile-young. html (accessed on 15 July 2018).

14. Beu, D.; Ciugudeanu, C.; Buzdugan, M. Circular Economy Aspects Regarding LED Lighting Retrofit-From Case Studies to Vision. Sustainability 2018, 10, 3674. [CrossRef]

15. Dolara, A.; Leva, S. Power Quality and Harmonic Analysis of End User Devices. Energies 2012, 5, 5453-5466. [CrossRef]

16. SR EN 12464 -1:2011. Light and Lighting-Lighting of Workplaces_Part 1: Indoor Workplaces; SR EN June 2011. Available online: http://magazin.asro.ro/en/standard/193427 (accessed on 11 December 2019).

17. Pourarab, M.; Nakhodchi, N.; Monfared, M. Harmonic Analysis of LED Street Lighting According to IEC 61000-3-2; A Case Study. In Proceedings of the 23rd International Conference on Electricity Distribution-CIRED 2015, Lyon, France, 15-18 June 2015. 
18. Shabbir, H.; Ur Rehman, M.; Rehman, S.A.; Sheikh, S.K.; Zaffar, N. Assessment of Harmonic Pollution by LED Lamps in Power Systems. In Proceedings of the Power Systems Conference (PSC), Clemson, SC, USA, 11-14 March 2014.

19. IEC 61000-3-2:2018. International Electrotechnical Commission, Electromagnetic Compatibility (EMC)—Part 3-2: Limits-Limits for Harmonic Current Emissions (Equipment Input Current $\leq 16$ A Per Phase); IEC. Available online: https://webstore.iec.ch/publication/28164 (accessed on 11 December 2019).

20. European Power Supply Manufacturers Association. Harmonic Current Emissions Guidelines to the Standard EN 61000-3-2; Revision Date: 2010-11-08; European Power Supply Manufacturers Association. Available online: http://www.epsma.org/PFCver100406_b.pdf (accessed on 11 December 2019).

21. Jettanasen, C.; Pothisarn, C. Analytical Study of Harmonics Issued from LED Lamp Driver. In Proceedings of the International Multi Conference of Engineers and Computer Scientists 2014, Vol. II, (IMECS 2014), Hong Kong, China, 12-14 March 2014.

22. Emission Factors in kg CO2-Equivalent Per Unit Source. Available online: https://www.winnipeg. ca/finance/findata/matmgt/documents/2012/682-2012/682-2012_Appendix_H-STP_South_End_Plant_ Process_Selection_Report/Appendix\%207.pdf (accessed on 1 August 2018).

23. Vandevoorde, A.; Zissis, G.; Mequignon, M.; Cressault, Y. Evaluation de L'impact Environnemental Du cycle de vie de Systèmes d'éclairage. In Proceedings of the 4th Conférence Francophone sur l'Eco-Conception et le Développement Durable en Génie Electrique CONFREGE 2016, Genève, Switzerland, 27-29 June 2016.

24. Phannil, N.; Jettanasen, C.; Ngaopitakkul, A. Harmonics and Reduction of Energy Consumption in Lighting Systems by Using LED Lamps. Energies 2018, 11, 3169. [CrossRef]

25. Lodetti, S.; Azcarate, I.; Gutiérrez, J.J.; Leturiondo, L.A.; Redondo, K.; Sáiz, P.; Melero, J.J.; Bruna, J. Flicker of Modern Lighting Technologies Due to Rapid Voltage Changes. Energies 2019, 12, 865. [CrossRef]

(C) 2019 by the authors. Licensee MDPI, Basel, Switzerland. This article is an open access article distributed under the terms and conditions of the Creative Commons Attribution (CC BY) license (http://creativecommons.org/licenses/by/4.0/). 